\title{
Optical and Electrical Properties of Mn-doped and Mn-Al co-doped ZnO Thin Films Annealed at Different Temperatures for Photosensor Applications
}

\author{
Ming-Yu Yen, ${ }^{1}$ Tao-Hsing Chen, ${ }^{2 *}$ Po-Hsun Lai, ${ }^{2}$ \\ Sheng-Lung Tu, ${ }^{1}$ Yun-Hwei Shen, ${ }^{1}$ and Chun-Chieh Huang ${ }^{3}$ \\ ${ }^{1}$ Department of Resources Engineering, National Cheng Kung University, Tainan City 701, Taiwan \\ ${ }^{2}$ Department of Mechanical Engineering, National Kaohsiung University of Science and Technology, \\ Kaohsiung City 807, Taiwan \\ ${ }^{3}$ Department of Electrical Engineering, Cheng Shiu University, Kaohsiung City 833, Taiwan
}

(Received May 23, 2021; accepted September 22, 2021; online published November 29, 2021)

Keywords: $\mathrm{Mn}$-doped $\mathrm{ZnO}, \mathrm{Mn}-\mathrm{Al}$ co-doped $\mathrm{ZnO}$, annealing, electrical, transmittance

Mn-doped and $\mathrm{Mn}-\mathrm{Al}$ co-doped zinc oxide $(\mathrm{ZnO})$ thin films were deposited on glass substrates by RF magnetron sputtering at room temperature. The X-ray diffraction results revealed that both films consisted of a single phase and had a wurtzite structure with a c-axis orientation. The electrical properties, transmittance characteristics, surface properties, and crystal structures of the films were investigated following annealing at temperatures ranging from 200 to $500{ }^{\circ} \mathrm{C}$. The results showed that the as-deposited $\mathrm{Mn}: \mathrm{ZnO}$ thin film had an average transmittance of $83 \%$. The transmittance increased to $85 \%$ following annealing at $500{ }^{\circ} \mathrm{C}$. The as-deposited $\mathrm{Mn}-\mathrm{Al}$ co-doped $\mathrm{ZnO}$ thin film had a low transmittance of only $40 \%$. However, after annealing at $500{ }^{\circ} \mathrm{C}$, the transmittance increased to $83 \%$. The annealed $\mathrm{Mn}-\mathrm{Al}: \mathrm{ZnO}$ thin film also showed a low electrical resistivity of $1.75 \times 10^{-3} \Omega \cdot \mathrm{cm}$, an electron mobility of $20.8 \mathrm{~cm}^{2} \mathrm{~V}^{-1} \mathrm{~s}^{-1}$, and a carrier concentration of $5.3 \times 10^{20} \mathrm{~cm}^{-3}$. Scanning electron microscopy (SEM) results showed that the crystal size of both thin films increased following annealing. Owing to their good optical and electrical properties, the annealed $\mathrm{Mn}-\mathrm{Al}: \mathrm{ZnO}$ thin films can be used as photosensor materials.

\section{Introduction}

Transparent conducting oxide (TCO) thin films are widely used in photoelectric devices such as liquid crystal displays, organic LEDs, photovoltaic batteries, thin-film solar cells, and photosensors. $^{(1-3)}$ Among the many different types of TCO material available nowadays, zinc oxide $(\mathrm{ZnO})$ has attracted particular attention due to its direct wide band gap, non-toxicity, low cost, and natural abundance. However, $\mathrm{ZnO}$ films have high electrical resistance, which hinders their practical application. ${ }^{(4-9)}$ Accordingly, the problem of improving the electrical performance of $\mathrm{ZnO}$ thin films through doping with metallic elements such as $\mathrm{Al}, \mathrm{Ga}, \mathrm{Ag}, \mathrm{Ti}, \mathrm{Zr}$, and Mo has

*Corresponding author: e-mail: thchen@nkust.edu.tw

https://doi.org/10.18494/SAM3555 
attracted significant attention in recent years. ${ }^{(10-15)}$ In such methods, the doped atoms substitute for the $\mathrm{Zn}$ atoms in the $\mathrm{ZnO}$ crystal structure and produce free electrons in the conduction band, which lower the electrical resistivity. One of the most widely used dopants of $\mathrm{ZnO}$ nanostructures is manganese $(\mathrm{Mn})$ due to its large number of free electrons in the electric band. Mn-doped $\mathrm{ZnO}$ thin films have been widely studied as magnetic semiconductors. ${ }^{(16-20)}$ Furthermore, several studies have investigated the effects of Mn doping on the structural morphology and optical properties of $\mathrm{ZnO} .^{(21,22)}$ However, the literature contains little information on the effects of $\mathrm{Mn}$ doping and $\mathrm{Mn}-\mathrm{Al}$ co-doping on the optoelectrical properties of $\mathrm{ZnO}$ following annealing at different temperatures.

TCO thin films can be deposited using many different methods, including molecular beam epitaxy (MPE), ${ }^{(23)}$ magnetron sputtering, ${ }^{(24,25)}$ sol-gel processing, ${ }^{(26)}$ chemical vapor deposition, ${ }^{(27)}$ pulsed laser deposition, and so forth. ${ }^{(28)}$ Among these methods, RF magnetron sputtering is one of the most commonly used for the deposition of $\mathrm{ZnO}$ thin films due to the ease with which the deposition parameters can be adjusted and controlled. ${ }^{(29,30)}$ Accordingly, in the present study, $\mathrm{Mn}$-doped and $\mathrm{Mn}-\mathrm{Al}$ co-doped $\mathrm{ZnO}$ thin films are deposited on glass substrates by a RF magnetron sputtering system at room temperature. The as-deposited films are annealed at various temperatures in the range of $200-500{ }^{\circ} \mathrm{C}$. The effects of the annealing temperature on the structural, optical, and electrical properties of the films are then investigated and compared. Good optical and electrical properties are observed for the $\mathrm{Mn}-\mathrm{Al}: \mathrm{ZnO}$ thin films after annealing, suggesting that they can be used as photosensor materials.

\section{Experimental Methodology and Characterization}

Corning glass substrates with dimensions of $50 \mathrm{~mm} \times 50 \mathrm{~mm} \times 7 \mathrm{~mm}$ (length $\times$ width $\times$ thickness) were cut into test pieces with a size of $25 \mathrm{~mm} \times 25 \mathrm{~mm} \times 7 \mathrm{~mm}$ using a diamond cutter. The test pieces were cleaned sequentially in de-ionized water, acetone, and isopropanol (IPA) to remove any non-organic contaminants and residual solvent and were then dried in an oven at $90{ }^{\circ} \mathrm{C}$. Mn-doped and $\mathrm{Mn}-\mathrm{Al}$ co-doped $\mathrm{ZnO}$ thin films were then deposited on the substrates using an RF magnetron sputtering system with sintered $\mathrm{ZnO}$ targets containing 5 at $\%$ $\mathrm{Mn}(\mathrm{Mn}: \mathrm{ZnO}$ thin film) and $5 \mathrm{at} \% \mathrm{Mn}$ and 3 at $\% \mathrm{Al}(\mathrm{Mn}-\mathrm{Al}: \mathrm{ZnO}$ thin film), respectively. Both sputtering targets were disk-shaped with dimensions of $75 \mathrm{~mm} \times 2 \mathrm{~mm}$ (diameter $\times$ thickness). A schematic diagram of the sputtering device is presented in Fig. 1. For both films, the deposition process was performed using a sputtering power, chamber pressure, deposition time, and targetto-substrate distance of $100 \mathrm{~W}, 4 \mathrm{mTorr}, 90 \mathrm{~min}$, and $6 \mathrm{~mm}$, respectively. Following the deposition process, half of the samples were annealed at a temperature of 200,300,400, or $500{ }^{\circ} \mathrm{C}$. The crystal growth was examined by X-ray diffraction (XRD, SIEMENS D-500) with $\mathrm{Cu}-\mathrm{K} \alpha$ radiation. The optical transmittance properties of the films were investigated using a UV-vis spectrophotometer (Hitachi 2900). The electrical properties were determined by Hall effect measurements (AHM-800B). Finally, the surface features and crystal size of the films were characterized by scanning electron microscopy (SEM, JSM-7000F). 


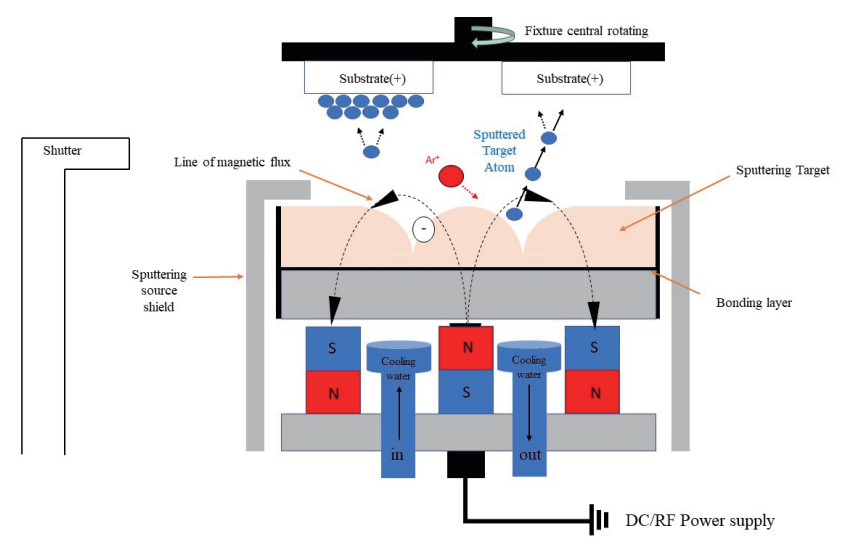

Fig. 1. (Color online) Schematic diagram of sputtering device.

\section{Results and Discussion}

\subsection{Structural characterization of $\mathrm{Mn}: \mathrm{ZnO}$ and $\mathrm{Mn}-\mathrm{Al}: \mathrm{ZnO}$ thin films}

Figure 2 presents the XRD patterns of the as-deposited and annealed $\mathrm{Mn}: \mathrm{ZnO}$ thin films. As shown, all of the films exhibit a typical $\mathrm{ZnO}$ crystal structure with strong peaks at around $34.45^{\circ}$ (corresponding to the (002) preferential orientation) and $62.68^{\circ}$ (corresponding to the (103) orientation). In other words, the films have a polycrystalline hexagonal structure with a preferential orientation along the c-axis perpendicular to the substrate. No other peaks are evident in the XRD patterns, which suggests that the Mn atoms either simply substitute for the $\mathrm{Zn}$ atoms in the original hexagonal lattice directly, or segregate in the non-crystalline region of the structure at the grain boundaries. ${ }^{(31)}$ The intensity of the diffraction peaks increases with increasing annealing temperature. Hence, it is inferred that the crystal growth of the $\mathrm{Mn}: \mathrm{ZnO}$ structure is enhanced at higher temperatures. Figure 3 presents the XRD analysis results for the $\mathrm{Mn}-\mathrm{Al}: \mathrm{ZnO}$ thin films. The locations and tendencies of the diffraction peaks are similar to those of the $\mathrm{Mn}: \mathrm{ZnO}$ thin films. Moreover, no peaks are observed for either dopant (Mn or Al). Hence, the films are again inferred to have a polycrystalline hexagonal structure with a preferential orientation along the c-axis perpendicular to the substrate.

\subsection{Transmittance analysis}

Figures 4 and 5 present the optical transmittance spectra of the $\mathrm{Mn}: \mathrm{ZnO}$ and $\mathrm{Mn}-\mathrm{Al}: \mathrm{ZnO}$ thin films, respectively. The $\mathrm{Mn}: \mathrm{ZnO}$ thin films have an average transmittance of $80 \%$ under the as-deposited condition and $83 \%$ after annealing, regardless of the annealing temperature. However, the $\mathrm{Mn}-\mathrm{Al}: \mathrm{ZnO}$ thin films have an average transmittance of only $40 \%$ under the asdeposited condition and $85 \%$ following annealing at $500{ }^{\circ} \mathrm{C}$. The low transmittance before annealing can be attributed to the $\mathrm{Al}$ content of the films, which acts as a mirror and reflects most of the incident light. However, the transmittance is significantly improved following annealing, with the transmittance increasing with the annealing temperature. For example, the 


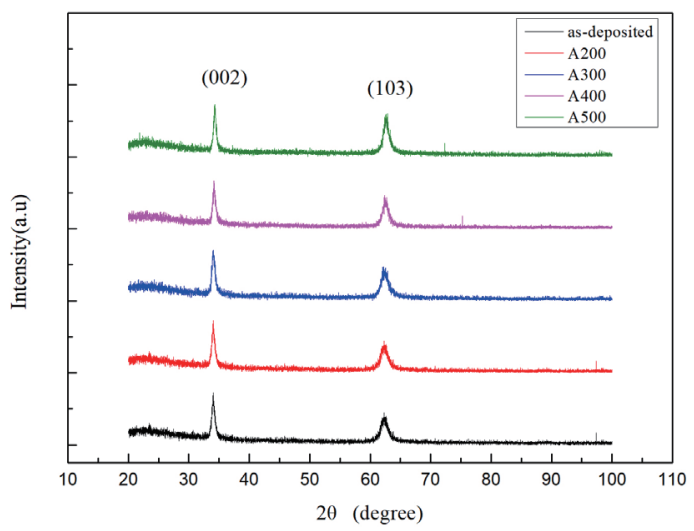

Fig. 2. (Color online) XRD spectra of $\mathrm{Mn}: \mathrm{ZnO}$ thin films annealed at different temperatures.

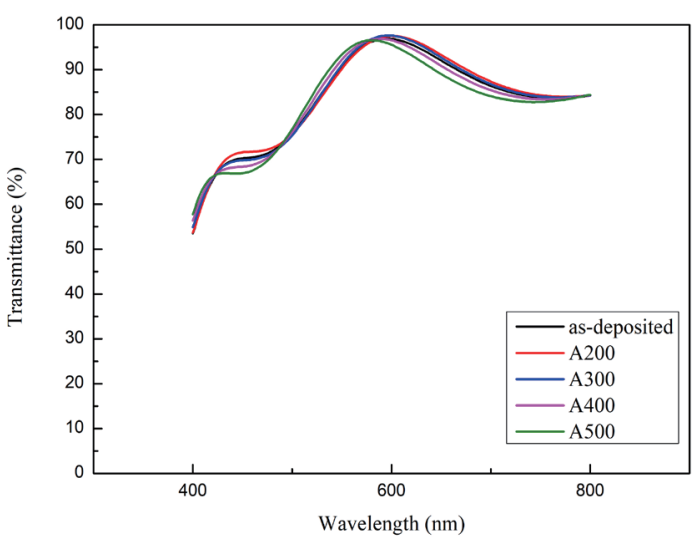

Fig. 4. (Color online) Transmittance properties of $\mathrm{Mn}: \mathrm{ZnO}$ thin films annealed at different temperatures.

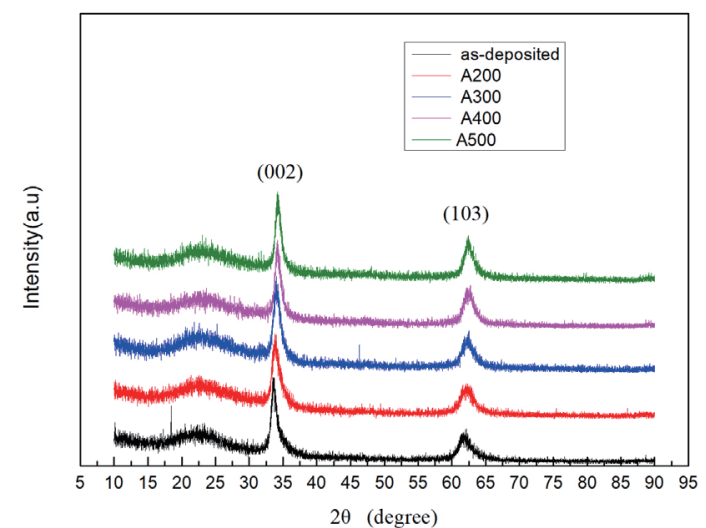

Fig. 3. (Color online) XRD spectra of Mn-Al codoped $\mathrm{ZnO}$ thin films annealed at different temperatures.

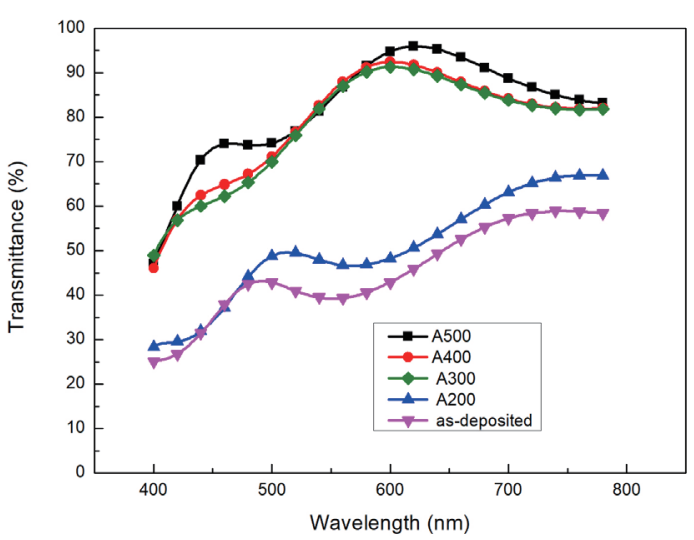

Fig. 5. (Color online) Transmittance properties of $\mathrm{Mn}-\mathrm{Al}$ co-doped $\mathrm{ZnO}$ thin films annealed at different temperatures.

maximum average transmittances are $78 \%$ and $85 \%$ following annealing at 300 and $500{ }^{\circ} \mathrm{C}$, respectively. The increase in transmittance is due to the reduction in the optical energy gap as a result of annealing.

In the case of direct transmission, the optical absorption coefficient of thin-film systems can be expressed as ${ }^{(32)}$

$$
(\alpha h v)^{2}=A\left(h v-E_{g}\right)
$$

where $A$ is a constant, $h v$ is the photon energy, and $E_{g}$ is the optical band gap energy. Figures 6 and 7 show the variation of the absorption coefficient $(a h v)^{2}$ with the photon energy $h v$ for the $\mathrm{Mn}: \mathrm{ZnO}$ and $\mathrm{Mn}-\mathrm{Al}: \mathrm{ZnO}$ thin films, respectively. For each film, the optical energy gap can be obtained by linear fitting of the absorption coefficient curves in the sharp absorption edge region 


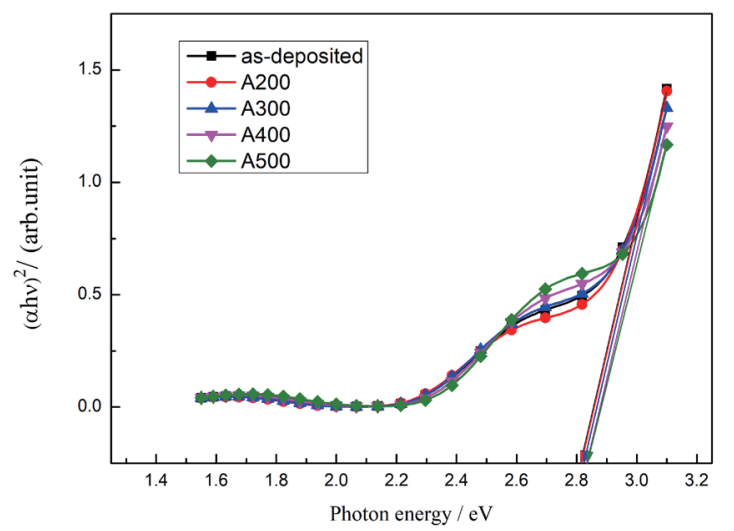

Fig. 6. (Color online) Energy gaps of $\mathrm{Mn}: \mathrm{ZnO}$ thin films annealed at different temperatures.

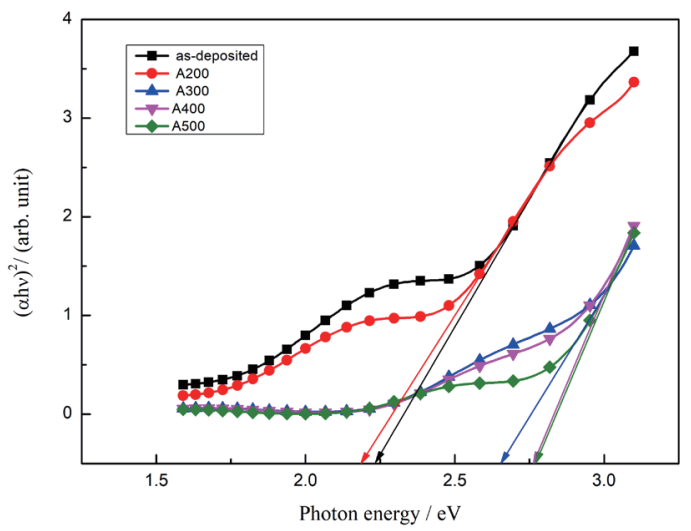

Fig. 7. (Color online) Energy gaps of $\mathrm{Mn}-\mathrm{Al}$ codoped $\mathrm{ZnO}$ thin films annealed at different temperatures.

of the figure. The optical energy gap of a conventional undoped $\mathrm{ZnO}$ film is $3.26 \mathrm{eV} .^{(29)}$ However, the results presented in Fig. 6 show that the energy gap of the present $\mathrm{Mn}: \mathrm{ZnO}$ thin films is only $2.82 \mathrm{eV}$. It is speculated that the reduction in the energy gap is most likely the result of $\mathrm{Zn}^{2+}$ and $\mathrm{Mn}^{2+}$ exchange interactions between the conduction band electrons in accordance with the so-called Burstein-Moss effect. ${ }^{(33,34)}$ Figure 7 similarly shows that the $\mathrm{Al}^{3+}, \mathrm{Mn}^{2+}$, and $\mathrm{Zn}^{2+}$ interactions between the conduction band electrons cause the energy gap to decrease to around $2.3 \mathrm{eV}$ in the as-deposited film and the film annealed at $200{ }^{\circ} \mathrm{C}$. However, following annealing at temperatures in the range of $300-500{ }^{\circ} \mathrm{C}$, the energy gap increases slightly to $2.75 \mathrm{eV}$ due to the diffusion of $\mathrm{Al}$ and $\mathrm{Mn}$ into the $\mathrm{ZnO}$ lattice structure.

\subsection{Electrical properties analysis}

Tables 1 and 2 show the electrical properties of the as-deposited and annealed $\mathrm{Mn}: \mathrm{ZnO}$ and $\mathrm{Mn}-\mathrm{Al}: \mathrm{ZnO}$ thin films, respectively. For both films, the electrical resistivity decreases with increasing annealing temperature due to the enhanced diffusion of the dopants ( $\mathrm{Mn}$ and $\mathrm{Al}$ ) into the $\mathrm{ZnO}$ structure. However, comparison of the results presented in the two tables shows that the $\mathrm{M}-\mathrm{Al}: \mathrm{ZnO}$ film has better electrical properties than the $\mathrm{Mn}: \mathrm{ZnO}$ film (i.e., lower resistivity and mobility and a higher carrier concentration). In general, $\mathrm{Al}^{3+}$ provides three free electrons and can be activated as effectively as oxygen vacancies. ${ }^{(35,36)}$ Furthermore, the carrier concentration in $\mathrm{Mn}: \mathrm{Al}: \mathrm{ZnO}$ is determined primarily by the concentration of oxygen vacancies. Therefore, the low resistivity of the $\mathrm{Mn}-\mathrm{Al}: \mathrm{ZnO}$ film annealed at $500{ }^{\circ} \mathrm{C}\left(1.75 \times 10^{-3} \Omega \cdot \mathrm{cm}\right)$ can be mainly attributed to the increase in the carrier concentration $\left(5.3 \times 10^{20} \mathrm{~cm}^{-3}\right)$.

\subsection{Surface features analysis}

Figures 8 and 9 present SEM images of the as-deposited and annealed $\mathrm{Mn}: \mathrm{ZnO}$ and $\mathrm{Mn}-\mathrm{Al}: \mathrm{ZnO}$ thin films, respectively. For both films, the grain size increases with increasing 
Table 1

Electrical properties of $\mathrm{Mn}: \mathrm{ZnO}$ thin films annealed at different temperatures.

\begin{tabular}{lccc}
\hline Temperature $\left({ }^{\circ} \mathrm{C}\right)$ & Resistivity $(\Omega \cdot \mathrm{cm})$ & Mobility $\left(\mathrm{cm}^{2} \mathrm{~V}^{-1} \mathrm{~s}^{-1}\right)$ & Carrier concentration $\left(\mathrm{cm}^{-3}\right)$ \\
\hline As-deposited & $3.42 \times 10^{-1}$ & 31.1 & $1.46 \times 10^{19}$ \\
200 & $1.51 \times 10^{-1}$ & 15.9 & $7.28 \times 10^{19}$ \\
300 & $5.83 \times 10^{-2}$ & 18.2 & $9.53 \times 10^{19}$ \\
400 & $3.87 \times 10^{-2}$ & 21.2 & $2.46 \times 10^{20}$ \\
500 & $2.1 \times 10^{-2}$ & 25.9 & $3.32 \times 10^{20}$ \\
\hline
\end{tabular}

Table 2

Electrical properties of $\mathrm{Mn}-\mathrm{Al}$ co-doped $\mathrm{ZnO}$ thin films annealed at different temperatures.

\begin{tabular}{lccc}
\hline Temperature $\left({ }^{\circ} \mathrm{C}\right)$ & Resistivity $(\Omega \cdot \mathrm{cm})$ & Mobility $\left(\mathrm{cm}^{2} \mathrm{~V}^{-1} \mathrm{~s}^{-1}\right)$ & Carrier concentration $\left(\mathrm{cm}^{-3}\right)$ \\
\hline As-deposited & $3.07 \times 10^{-2}$ & 25.9 & $8.1 \times 10^{19}$ \\
200 & $2.2 \times 10^{-2}$ & 13.9 & $9.28 \times 10^{19}$ \\
300 & $7.4 \times 10^{-3}$ & 16.2 & $1.5 \times 10^{20}$ \\
400 & $3.8 \times 10^{-3}$ & 18.5 & $3.7 \times 10^{20}$ \\
500 & $1.75 \times 10^{-3}$ & 20.8 & $5.3 \times 10^{20}$ \\
\hline
\end{tabular}

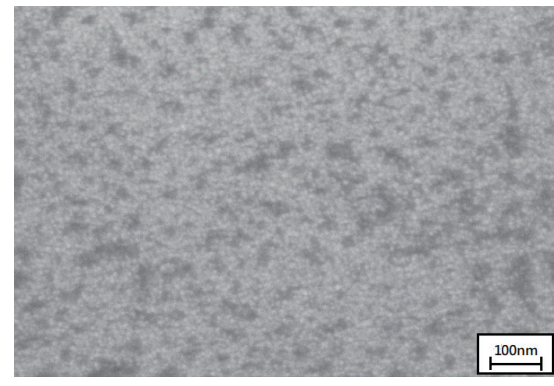

(a)

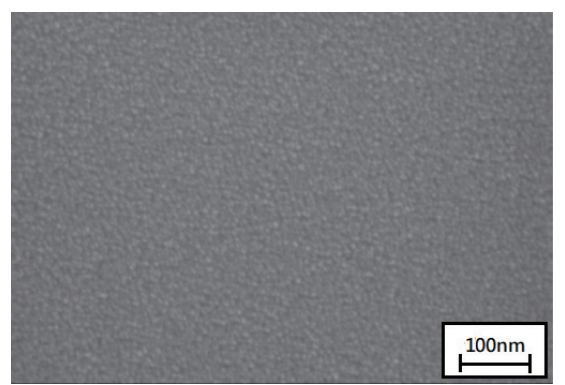

(c)

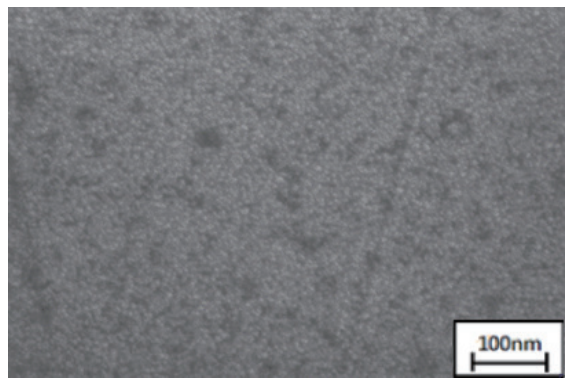

(b)

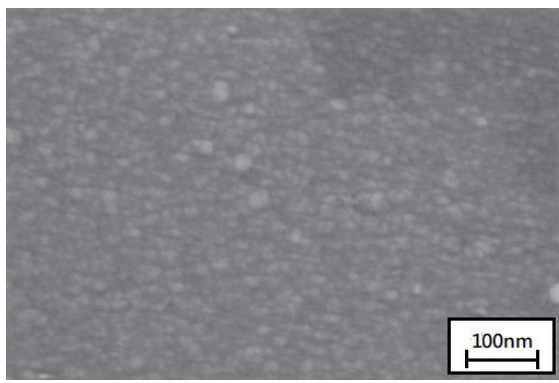

(d)

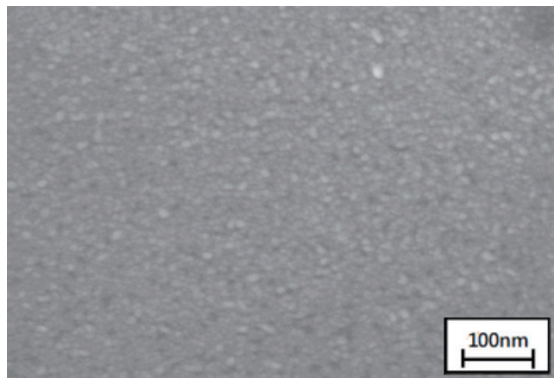

(e)

Fig. 8. SEM images of $\mathrm{Mn}: \mathrm{ZnO}$ thin films: (a) as-deposited and (b)-(e) following annealing at temperatures of (b) $200{ }^{\circ} \mathrm{C}$, (c) $300{ }^{\circ} \mathrm{C}$, (d) $400{ }^{\circ} \mathrm{C}$, and (e) $500{ }^{\circ} \mathrm{C}$. 


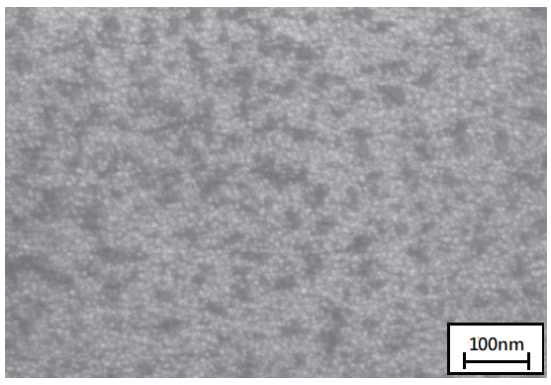

(a)

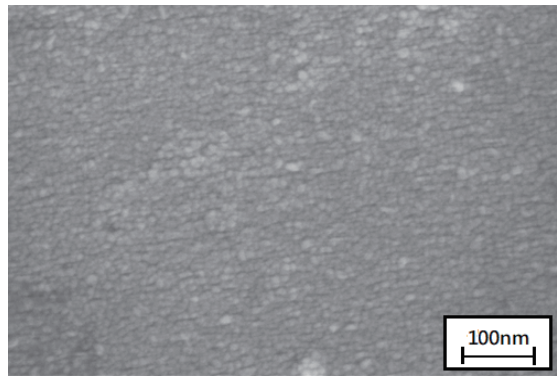

(c)

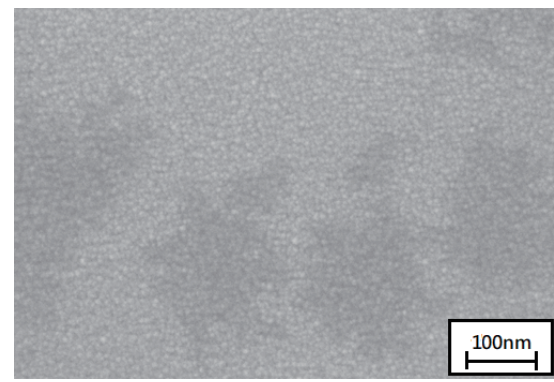

(b)

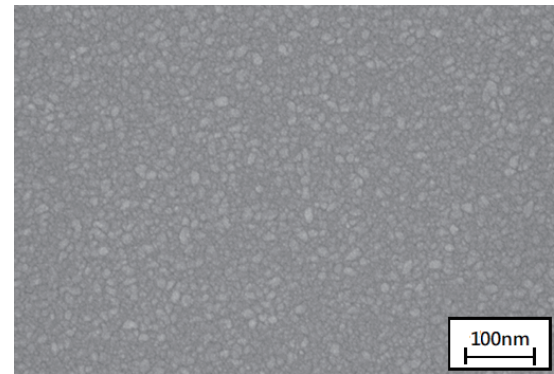

(d)

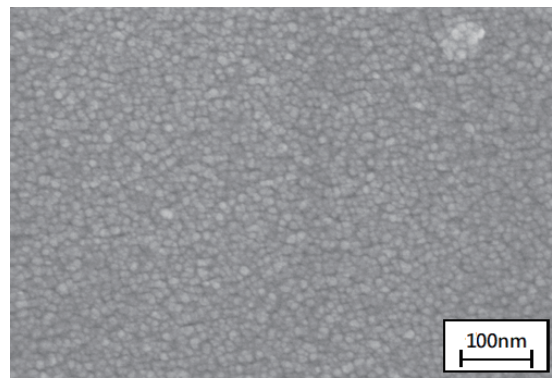

(e)

Fig. 9. SEM images of $\mathrm{Mn}-\mathrm{Al}: \mathrm{ZnO}$ thin films: (a) as-deposited and (b)-(e) following annealing at temperatures of (b) $200{ }^{\circ} \mathrm{C}$, (c) $300{ }^{\circ} \mathrm{C}$, (d) $400{ }^{\circ} \mathrm{C}$, and (e) $500{ }^{\circ} \mathrm{C}$.

annealing temperature. For example, the crystal grain size of the $\mathrm{Mn}: \mathrm{ZnO}$ thin film increases from $25.4 \mathrm{~nm}$ under the as-deposited condition to $45.3 \mathrm{~nm}$ following annealing at $500{ }^{\circ} \mathrm{C}$. Similarly, for the $\mathrm{Mn}-\mathrm{Al}: \mathrm{ZnO}$ film, the crystal grain size increases from $28.3 \mathrm{~nm}$ before annealing to $49.5 \mathrm{~nm}$ after annealing at $500^{\circ} \mathrm{C}$.

The grain size is related to the full width at half maximum (FWHM) of the peak in the corresponding XRD pattern in accordance with the Scherrer formula: ${ }^{(37)}$

$$
D=0.9 \lambda / \beta \cos \theta,
$$

where $D$ is the grain size, $\beta$ is the FWHM value of the XRD peak, $\lambda$ is the wavelength of the incident light, and $\cos \theta$ is the diffraction angle. In practice, $\lambda$ and $\cos \theta$ have constant values in the XRD measurement process, and thus the grain size is mainly associated with the FWHM value $(\beta)$. Tables 3 and 4 list the grain size and FWHM value of each of the $\mathrm{Mn}: \mathrm{ZnO}$ and 
Table 3

Grain size and FWHM values of $\mathrm{Mn}: \mathrm{ZnO}$ thin films annealed at different temperatures.

\begin{tabular}{lcc}
\hline Annealing temperature $\left({ }^{\circ} \mathrm{C}\right)$ & FWHM & Grain size $(\mathrm{nm})$ \\
\hline As-deposited & 0.528 & 25.4 \\
200 & 0.49 & 30.9 \\
300 & 0.45 & 35.06 \\
400 & 0.41 & 42.13 \\
500 & 0.38 & 45.3 \\
\hline
\end{tabular}

Table 4

Grain size and FWHM values of $\mathrm{Mn}-\mathrm{Al}$ co-doped $\mathrm{ZnO}$ thin films annealed at different temperatures.

\begin{tabular}{lcc}
\hline Annealing temperature $\left({ }^{\circ} \mathrm{C}\right)$ & FWHM & Grain size $(\mathrm{nm})$ \\
\hline As-deposited & 0.55 & 28.3 \\
200 & 0.51 & 32.5 \\
300 & 0.45 & 38.2 \\
400 & 0.38 & 44.6 \\
500 & 0.32 & 49.5 \\
\hline
\end{tabular}

$\mathrm{Mn}-\mathrm{Al}: \mathrm{ZnO}$ films. As expected from Eq. (2), the grain size increases with decreasing FWHM in both sets of films. ${ }^{(38)}$

\section{Conclusions}

We have investigated the structural, optical, and electrical properties of $\mathrm{Mn}: \mathrm{ZnO}$ and $\mathrm{Mn}-\mathrm{Al}: \mathrm{ZnO}$ thin films deposited on glass substrates using an RF magnetron sputtering system and annealed at various temperatures in the range of $200-500{ }^{\circ} \mathrm{C}$. The XRD results showed that all of the films exhibit strong diffraction peaks corresponding to the (002) and (103) preferential orientations. Moreover, no peaks associated with $\mathrm{Mn}$ or Al metal phases were observed. Hence, it was inferred that both films consist of a single phase and have a wurtzite structure with a c-axis orientation. Of the two sets of films, the $\mathrm{Mn}: \mathrm{ZnO}$ thin films have a higher average transmittance than the $\mathrm{Mn}-\mathrm{Al}: \mathrm{ZnO}$ films since the Al metal element causes light scattering. However, for both sets of films, the average transmittance increases with increasing annealing temperature due to the corresponding reduction in the energy gap (i.e., 2.82 and $2.75 \mathrm{eV}$ for the $\mathrm{Mn}: \mathrm{ZnO}$ and $\mathrm{Mn}-\mathrm{Al}: \mathrm{ZnO}$ films following annealing at $500{ }^{\circ} \mathrm{C}$, respectively). The $\mathrm{Mn}-\mathrm{Al}: \mathrm{ZnO}$ films have a better electrical performance than the $\mathrm{Mn}-\mathrm{ZnO}$ films due to the $\mathrm{Al}$ dopant, which provides a greater number of free electrons to the conduction band. For both films, the electrical resistivity decreases with increasing annealing temperature as a result of the diffusion of $\mathrm{Mn}$ and $\mathrm{Al}$ elements into the $\mathrm{ZnO}$ thin film, which enhances the electrical properties. For the maximum annealing temperature of $500{ }^{\circ} \mathrm{C}$, the $\mathrm{Mn}: \mathrm{ZnO}$ and $\mathrm{Mn}-\mathrm{Al}: \mathrm{ZnO}$ films have resistivities of $2.1 \times 10^{-2}$ and $1.75 \times 10^{-3} \Omega \cdot \mathrm{cm}$, respectively. For both sets of films, the crystal grain size increases with increasing annealing temperature due to the enhanced crystal growth at higher temperatures. According to the results presented in this study, the optical and electrical 
properties of the $\mathrm{Mn}: \mathrm{ZnO}$ and $\mathrm{Mn}-\mathrm{Al}: \mathrm{ZnO}$ films are enhanced by annealing, enabling the films to be used in optical sensors or solar cells.

\section{Acknowledgments}

The authors gratefully acknowledge the financial support provided to this study by the Ministry of Science and Technology, Taiwan, under Project Nos. MOST 109-2221-E-992 -010 and MOST 110-2731-M-006-001.

\section{References}

1 K. Fleischer, E. Arca, and I. V. Shvets: Sol. Energy Mater. Sol. Cells 101 (2012) 262. https://doi.org/10.1016/j. solmat.2012.01.037

2 M. Nisha, S. Anusha, A. Antony, R. Manoj, and M. K. Jayaraj: Appl. Surf. Sci. 252 (2005) 1430. https://doi. org/10.1016/j.apsusc.2005.02.115

3 H. Zhang, C. Lei, H. F. Liu, and C. Yua: Appl. Surf. Sci. 255 (2009) 6054. https://doi.org/10.1016/j. apsusc.2009.01.043

4 C. F. Liu, T. H. Chen, and J. T. Huang: Sens. Mater. 32 (2020) 3727. https://doi.org/10.18494/SAM.2020.3138

5 P. Nunes, E. Fortunato, P. Tonello, F. B. Fernandes, P. Vilarinho, and R. Martins: Vacuum 64 (2002) 281. https://doi.org/10.1016/S0042-207X(01)00322-0

6 K. T. Lam, S. J. Young, Y. L. Chu, C. N. Tsai, T. T. Chu, T. S. Lu, and L. W. Ji: J. Nanomater. 2021 (2021) 6649200. https://doi.org/10.1155/2021/6649200

7 S. J. Young and Y. S. Liu: IEEE J. Electron Devices Soc. 9 (2021) 265. http://ieeexplore.ieee.org/ document $/ 9340354$

8 S. J. Young, Y. H. Liu, M. D. Nahin Islam Shiblee, K. Ahmed, L. T. Lai, L. Nagahara, T. Thundat, T. Yoshida, S. Arya, H. Furukawa, and A. Khosla: ACS Appl. Electron. Mater. 2 (2020) 3522. https://doi.org/10.1021/ acsaelm.0c00556

9 S. J. Yang Y. H. Liu, S. J. Chang, and C. F. Chiu: ACS Omega 5 (2020) 27566. https://doi.org/10.1021/ acsomega.0c04136

10 F. H. Wang and C. L. Chang: Appl. Surf. Sci. 370 (2016) 83. https://doi.org/10.1016/j.apsusc.2016.02.161

11 T. H. Chen and H. T. Su: Sens. Mater. 30 (2018) 2541. https://doi.org/10.18494/SAM.2018.2056

12 T. H. Chen and C. L. Yang: Opt. Quantum Electron. 48 (2016) 533. https://doi.org/10.1007/s11082-016-0808-3

13 T. H. Chen and T. Y. Chen: Nanomaterials 5 (2015) 1831. https://doi.org/10.3390/nano5041831

14 S. Chattopadhyay, S. Dutta, A. Banerjee, D. Jana, S. Bandyopadhyay, S. Chattopadhyay, and A. Sarkar: Physica B 404 (2009) 1509. https://doi.org/10.1016/j.physb.2009.01.008

15 V. Gokulakrishnan, S. Parthiban, K. Jeganathan, and K. Ramamurthi: Appl. Surf. Sci. 257 (2011) 9068. https:// doi.org/10.1016/j.apsusc.2011.05.102

16 P. Singh, A. Kaushal, and D. Kaur: J. Alloys Compd. 471 (2009) 11. https://doi.org/10.1016/j.jallcom.2008.03.123

17 H. F. Zhang, R. J. Liu, H. F. Liu, C. X. Lei, D. T. Feng, and C. K. Yuan: Mater. Lett. 64 (2010) 605. https://doi. org/10.1016/j.matlet.2009.12.015

18 Z. F. Wu, X. M. Wu, L. J. Zhuge, B. Hong, X. M. Yang, T. Yu, J. J. He, and Q. Chen: Appl. Surf. Sci. 256 (2010) 2259. https://doi.org/10.1016/j.apsusc.2009.10.049

19 D. Hu, X. Liu, S. Deng, Y. Liu, Z. Feng, and B. Han: Physica E 61 (2014) 14. https://doi.org/10.1016/j. physe.2014.03.007

20 R. Mimouni, O. Kamoun, A. Yumak, A. Mhamdi, K. Boubaker, P. Petkova, and M. Amlouk: J. Alloys. Compd. 645 (2015) 100. https://doi.org/10.1016/j.jallcom.2015.05.012

21 S. Fabbiyola, L. J. Kennedy, A. A. Dakhel, M. Bououdina, J. J. Vijaya, and T. Ratnaji: J. Mol. Struct. 1109 (2016) 89. https://doi.org/10.1016/j.molstruc.2015.12.071

22 D. Milivojević, J. Blanuša, V. Spasojević, V. Kusigerski, and B. Babić-Stojić: Solid State Commun. 141 (2007) 641. https://doi.org/10.1016/j.ssc.2007.01.019

23 T. Ohgaki, N. Ohashi, H. Kakemoto, S. Wada, Y. Adachi, H. Haneda, and T. Tsurumi: J. Appl. Phys. 93 (2003) 1961. https://doi.org/10.1063/1.1535256

24 V. R. Shinde, T. P. Gujar, C. D. Lokhande, R. S. Mane, and S. H. Han: Mater. Chem. Phys. 96 (2006) 326. https://doi.org/10.1016/j.matchemphys.2005.07.045 
31 M. G. Sousa and A.

34 Y. Wang and W. Tang: Solid-State Electron. 138 (2017) 79. https://doi.org/10.1016/j.sse.2017.09.007

35 M. M. Rahman, M. K. R. Khan, M. R. Islam, M. A. Halim, M. Shahjahan, M. A. Hakim, D. K. Saha, and J. U. Khan: J. J. Mater. Sci. Technol. 28 (2012) 329. https://doi.org/10.1016/S1005-0302(12)60064-4

36 M. Frank and S. Arvids: J. Phys. Chem. Solids. 71 (2010) 784. https://doi.org/10.1016/j.jpcs.2010.02.001

37 M. Caglar, S. Ilican, and Y. Caglar: Thin Solid Films 517 (2009) 5023. https://doi.org/10.1016/j.tsf.2009.03.037

\section{About the Authors}

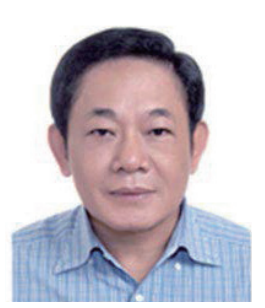

Ming-Yu Yen graduated from the Executive Master of Business Administration (EMBA) program of National Sun Yat-Sen University in 2015. He has been studying under the human resource management Ph.D. Program of National Sun Yat-Sen University and the resources engineering Ph.D. Program of National Chen Kung University since 2015 and 2017, respectively. His recent publications can be found in RCIS and SAGE journals.

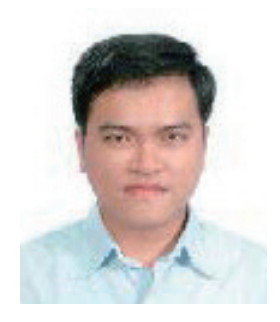

Tao-Hsing Chen received his B.S. degree from National Cheng Kung University, Taiwan, in 1999 and his M.S. and Ph.D. degrees from the Department of Mechanical Engineering, National Cheng Kung University, in 2001 and 2008, respectively. From August 2008 to July 2010, he was a postdoctoral researcher at the Center for Micro/Nano Science and Technology, National Cheng Kung University. In August 2010, he became an assistant professor at National Kaohsiung University of Applied Sciences (renamed National Kaohsiung University of Science and Technology), Taiwan. Since 2016, he has been a professor at National Kaohsiung University of Science and Technology. His research interests are in metal materials, TCO thin films, thermal sensors, and photosensors. (thchen@,nkust.edu.tw)

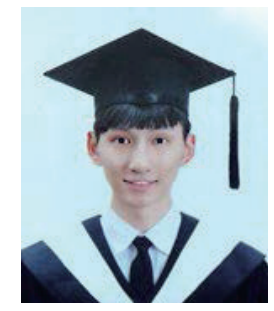

Po-Hsun Lai received his B.S. degree from National Kaohsiung University of Science and Technology, Taiwan, where he is currently studying for his M.S. degree. His research interests are in MEMS, materials engineering, and sensors. 

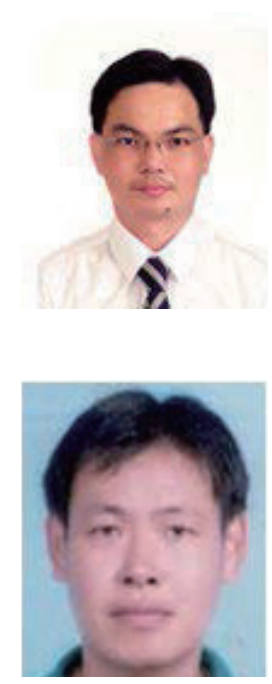

Sheng-Lung Tu received his M.S. degree from the Department of Mechanical Engineering, National Cheng Kung University, in 2010 and his Ph.D. degree from the Department of Resources Engineering, National Cheng Kung University, in 2014. Since 2014, he has worked as a general affairs officer at National Cheng Kung University. His research interests are in PVD technology, thin film technology, and sensors.

Yun-Hwei Shen received his B.S. degree from the Department of Mineral and Petroleum Engineering, National Cheng Kung University, in 1982, his M.S. degree from the University of Alaska Fairbanks, Mineral Preparation Engineering, USA, in 1987, and his Ph.D. degree from the Department of Environmental Engineering, Penn. State University, USA, in 1992. Since 1999, he has been a professor at the Department of Resources Engineering, National Cheng Kung University. His research interests are in catalysis technology, hydrometallurgical processing of resource materials, sensors, and hydrometallurgical processes.

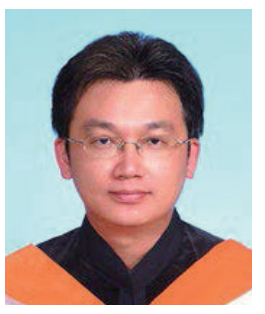

Chun-Chieh Huang received his B.S. degree from the Department of Mechanical Engineering, National Sun Yat-Sen University, in 1994, his M.S. degree from the Department of Materials Science and Engineering, National Cheng Kung University, in 1996, and his Ph.D. degree from the Department of Materials Science and Engineering, National Cheng Kung University, in 2007. He became an assistant professor at the Department of Electrical Engineering, Cheng Shu University, in 2008, where he has been an associate professor since 2014. His research interests are in optical and electrical thin films, optical sensors, and functional ceramics. 